\title{
Richard the Lionheart and the Ferocious Saladin Face to Face in Arsuf: A Proteomic Study
}

\author{
Gleb Zilberstein ${ }^{1}$, Svetlana Zilberstein ${ }^{1}$ and Pier Giorgio Righetti ${ }^{2, *}$ \\ 1 Spectrophon Ltd., Oppenheimer 7, Rehovot 7670107, Israel; post4gleb@gmail.com (G.Z.); \\ svetzilber@gmail.com (S.Z.) \\ 2 Department of Chemistry, Materials and Chemical Engineering "Giulio Natta", Politecnico di Milano, \\ Via Mancinelli 7, 20131 Milano, Italy \\ * Correspondence: piergiorgio.righetti@polimi.it
}

Citation: Zilberstein, G.;

Zilberstein, S.; Righetti, P.G. Richard the Lionheart and the Ferocious

Saladin Face to Face in Arsuf: A

Proteomic Study. Heritage 2021, 4 , 3382-3401. https://doi.org/10.3390/ heritage 4040188

Academic Editors:

Francesco Soldovieri and Arlen F. Chase

Received: 7 August 2021

Accepted: 4 October 2021

Published: 14 October 2021

Publisher's Note: MDPI stays neutral with regard to jurisdictional claims in published maps and institutional affiliations.

Copyright: (C) 2021 by the authors. Licensee MDPI, Basel, Switzerland. This article is an open access article distributed under the terms and conditions of the Creative Commons Attribution (CC BY) license (https:/ / creativecommons.org/licenses/by/ $4.0 /)$.

\begin{abstract}
On 7 September 1191, a fierce battle took place in Arsuf (Palestine) between the Crusaders (marching south towards Jerusalem) led by King Richard the Lionheart and the Ayyubid army commanded by the sultan Saladin. The confrontation lasted for most of the day and terminated with a victory of the Crusaders, proving Richard's courage as a soldier and his skill as a commander while denting Saladin's reputation as an invincible warrior. The site (today known as Apollonia) holds the ruins of a Crusader castle perched on a cliff over the sea. We recovered plenty of pottery shards among which we could distinguish those of the Crusaders from those of the Ayyubid army. Extraction of food remnants confirmed that the Crusaders' diet consisted mostly of pig and sheep meat (together with cheese), with a minimum of carbohydrates (what today would be termed a "ketogenic" diet), whereas the Muslim army consumed mostly carbohydrates (wheat, Triticum durum, Hordeum vulgare), together with fruits and vegetables, with minimal levels of sheep meat and cheese. As a result, the Crusaders' diet had a positive effect on their slenderness and "cardio". This might have been why the Ayyubid army lost ca. 10 times more soldiers in Arsuf. Shrewdness of leaders and soldiers' equipment and willingness to fight are, of course, the main ingredients of victory, but diet too might not have a secondary role and help to tip the balance.
\end{abstract}

Keywords: Third Crusade; Battle of Arsuf; Richard the Lionheart; Salah ad-Din; Crusader's diet; Muslim diet

\section{Introduction}

Whereas some catastrophic events such as Word War I and II are still vivid in our memories, most of us have forgotten that for close to 200 years (1096 to 1285), we Europeans pestered the Muslim world with the Crusades in the Holy Land. There was not just one crusade, but as many as eight, starting with that depreciable event of 27 November 1095 in Clermont when Pope Urban II was persuaded by a monk, Pierre d'Amiens, to open the flood of a series of aggressions in Palestine. There is a vast body of literature on the Crusades, which we have summarized in a list of 14 books [1-14] included in the Reference section (truly minimal, considering that J. Richard, in his book, dedicates 10 pages at the end of his treatise to catalog a much larger collection) [14].

Even if most of these events have fallen into oblivion, at least two major figures have remained in our collective memories, King Richard the Lionheart and his opponent, the "Ferocious" Saladin. There is a most curious story in Italy related to Saladin. In 1936, two companies, Perugina and Buitoni, launched a competition offering, as a prize, a Fiat 500 Topolino to anyone who could complete the collection of 150 lithographed color stamps, the premium one being the image of Saladin. The fact is that nobody could find this stamp, and this generated a stampede among the entire Italian population searching for the missing item and attempting any possible exchange among collectors. The search had become so paroxysmal that the fascist government, on 10 November 1937, via the Ministry 
of Corporation, decreed a total ban on any such collection. Meanwhile, a movie by Mario Bonnard, Il Feroce Saladino, appeared telling the story of a person who had found a catch of such stamps and had become filthy rich by selling them underground.

The events leading to a confrontation between the two leaders took place during the Third Crusade (1189-1192), in which the rulers of the three most powerful states of Western Christianity (England, France and the Holy Roman Empire) moved together to reconquer the Holy Land following the capture of Jerusalem by the Ayyubid sultan Saladin in 1187. It was partially successful, recapturing the important cities of Acre and Jaffa, and reversing most of Saladin's conquests, but it failed to capture Jerusalem, which was the major aim of the Crusade and its religious focus. In April 1190, King Richard's fleet departed from Dartmouth but reached Acre (that was already under siege by the Crusaders) on 8 June 1191. He immediately began supervising the construction of siege weapons to assault the city, which was captured on 12 July. After the seizure of Acre, King Richard decided to march to the city of Jaffa, since the control of this town was necessary before an attack on Jerusalem could be attempted. On 7 September 1191, however, Saladin attacked Richard's army at Arsuf, $50 \mathrm{~km}$ north of Jaffa. Saladin attempted to harass Richard's army into breaking its formation in order to defeat its isolated ranks. Richard maintained his army's defensive formation, however, until the Hospitallers broke ranks to charge the right wing of Saladin's forces. Richard then ordered a general counterattack, which won the battle. Arsuf was an important victory. The Muslim army lost 7000 soldiers. Arsuf dented Saladin's reputation as an invincible warrior and proved Richard's courage as a soldier and his skills as a commander.

Today, the site of Arsuf has been totally abandoned and hosts the ruins of a Crusader castle perched on a cliff overlooking the seashore. We visited this site and dug up plenty of pottery shards among which we could distinguish those of the Crusaders from those of the Ayyubid army. Extraction of food remnants and their proteomic analysis provided us important clues on the different diets of the two armies, as illustrated in this manuscript.

\section{Materials and Methods}

\subsection{Samples}

Crusaders' pottery: ceramic glazed pottery fragments; ceramic pottery fragments; glass fragments (glassware produced in Apollonia glassmaking workshops; glassware fragments coated with golden leaf). Saladin's warriors' pottery: ceramic pottery fragments; terracotta pottery fragments. Samples of pottery fragments were obtained during the "Tel Baruch-Arsuf 2020 Climate change monitoring" expedition. The samples in the catalog of the expedition that were analyzed are from TA-17 to TA-211 (thus, the total number of samples we had available is 194).

\subsection{Chemicals and Materials}

Methanol (LC-MS Ultra CHROMASOLV, >99.9\%), 2-propanol (LC-MS Ultra CHROMASOLV, $>99.9 \%$ ), acetic acid (eluent additive for LC-MS, $>99.9 \%$ ), ammonium bicarbonate (AMBIC), dithiothreitol (DTT), iodoacetamide, formic acid (FA, eluent additive for LC-MS, $>99.9 \%$ ), ammonium bicarbonate (AMBIC), trifluoroethanol (TFE) (>99\%), ammonium hydroxide and water (LC-MS Ultra CHROMASOLV, $>99.9 \%$ ) were purchased from SigmaAldrich (Milwaukee, WI, USA). Microcon YM-5 and C18 Zip Tip pipette tips were from Millipore U.K. Limited. Trypsin was from Promega, USA. Acclaim PepMap C18 columns were from Thermo Scientific, USA. Ultrapure water was obtained through a Millipore Milli-Q system (Milford, CT, USA). The mixed-bed cation (SCX)/anion (SAX) exchange AG501 resin and C8 and C18 resins were from Bio-Rad (Hercules, CA, USA).

\subsection{Synthesis and Characterization of the EVA Film}

A special plastic-like film based on ethylene-vinyl acetate (EVA) as a binder of ground AG501 mix-bed cation/anion exchange and C8 and C18 resins (all from Bio-Rad) was prepared. A mixture was made comprising 70\% 1-10 $\mu \mathrm{m}$ size ground beads and 30\% EVA (the 
melting temperature was $75^{\circ} \mathrm{C}$ ). The proportion of the various resins in the plastic film was: $35 \%$ strong cation, 35\% strong anion exchangers, 15\% C8 and 15\% C18 hydrophobic resins. The blend of melted EVA and Bio-Rad resins was poured in a "Brabender" mixer W30 and laminated via a "Brabender" extruder KE19 (both from Brabender GmbH, Duisburg, Germany) in the form of either a thin film or diskettes, having a thickness of 200 to $300 \mu \mathrm{m}$.

\subsection{EVA Film Application}

EVA films (width $50 \mathrm{~mm}$, length $50 \mathrm{~mm}$ ) were wetted in double distilled water prior to their applications to the surface of the specimens under investigation and then blotted on Whatman 3MM paper. They were placed on the pottery or glass test areas for $120 \mathrm{~min}$ while applying light pressure via a $100 \mathrm{~g}$ weight (but in difficult cases, the contact time was continued for a few days). All material harvested by the EVA thin diskettes was eluted and analyzed for proteins.

\subsection{Mass Spectrometry Analysis for Protein Identifications}

The dried eluates were suspended in $8 \mathrm{M}$ urea, reduced by $5 \mathrm{mM}$ DTT and alkylated by $15 \mathrm{mM}$ iodoacetamide. The buffer was exchanged by a filter unit with a $5 \mathrm{kDa}$ cut-off, using $50 \mathrm{mM}$ AMBIC. The proteins were digested by $0.5 \mu \mathrm{g}$ of trypsin, overnight at $37^{\circ} \mathrm{C}$. The peptide mixtures were purified by C18 pipette tips and analyzed by nLC MS/MS, using a MALDI TOF mass spectrometer (Voyager; ABI, Framingham, MA, USA) with the following settings: $25 \mathrm{kV}$ accelerating voltage, $94.5 \%$ grid voltage and $350 \mathrm{~ns}$ delay. The peptides were separated, after trapping on a C18 pre-column, by using a gradient of $3-40 \%$ acetonitrile in $0.1 \%$ formic acid, over $50 \mathrm{~min}$ at a flow rate of $300 \mathrm{~nL} / \mathrm{min}$, at $40{ }^{\circ} \mathrm{C}$. The separation system consisted of EASY-nLC. A solid ionic crystal MALDI matrix of paranitroaniline and butyric acid was used. The raw data were analyzed by Mascot (version 2.4.1) by consulting plant and animal protein databases. The peptide tolerance was 30 ppm. The false discovery rate was below $0.1 \%$, using a decoy database, and the identified proteins contained at least 3 peptides.

\subsection{Extraction and Sample Preparation Tools for Archeology Field Analysis}

New tools for extracting biomolecules from fragments and fragments of various artifacts from archaeological horizons are sorely needed. In Apollonia, Arsuf and other places, there are huge archaeological layers (horizons) that come to the surface of the soil due its erosion. We have created several new tools based on EVA technology. The first instrument is an EVA probe. The probe can be thrust into an archaeological horizon (layer) that contains shards of utensils and extract proteins, peptides, salts and much more. The second tool is a special bag for archaeological material. Usually, archaeologists collect all their samples with archaeological fragments in bags. The soil from archeology horizons is kept in these special bags. In a bag with EVA inserts, the sample can be automatically extracted from the soil. This process is carried out from the soil already in this special bag. The third tool consists in tanks or flexible bags made with EVA inserts. In these tanks or bags, one can insert a shard of a dish or another sample for the extraction of biological molecules directly at the archaeological site.

\subsection{Calorie Consumption and Diet Efficiency Estimations}

To calculate the calorie content of diets, many online calculators for individual use have recently been created. In our study, different versions of nutritional calorie and value calculators were used, and an estimate of the effectiveness of the diets of the Crusaders and Saladin's warriors was obtained: https: / / www.webmd.com/diet/healthtool-food-caloriecounter; https: / / www.mayoclinic.org/healthy-lifestyle/weight-loss/in-depth/caloriecalculator /itt-20402304 (accessed on 3 June 2021). However, we underline that it cannot be expected (and possible) that the calorie and nutritional calculators provided here as links could be used to estimate the effectiveness of the Crusaders' and Saladin's warriors' diets, as it is impossible to determine the exact amounts and foods the warriors ate. We here add 
that the discussion of the diet of the two armies of two different religions is by no means only a scientific issue, but also a cultural and religious issue. Halalism among Muslims and different dietary variations among Saladin's multinational Muslim army should be considered together with cultural and religious issues in the text of our report. The diet of the multinational Crusader army must also be considered in conjunction with cultural aspects. One of the warfare tactics was the supply of poisoned wine to the Christian troops. It is thus seen that the question of the diets of the two armies is a fairly complex issue.

\section{Results}

\subsection{A Survey of the Territory}

In order to understand the events, it is necessary to carry out a survey of the land. Figure 1 displays a map of the Middle East area where all crusades took place. The principalities of Armenian Cilicia and of Antioch, as well as the County of Tripoli, had already been established in the two previous crusades. The major events of the Third Crusade occurred mainly in the stretch of land between Tyre and Jerusalem.

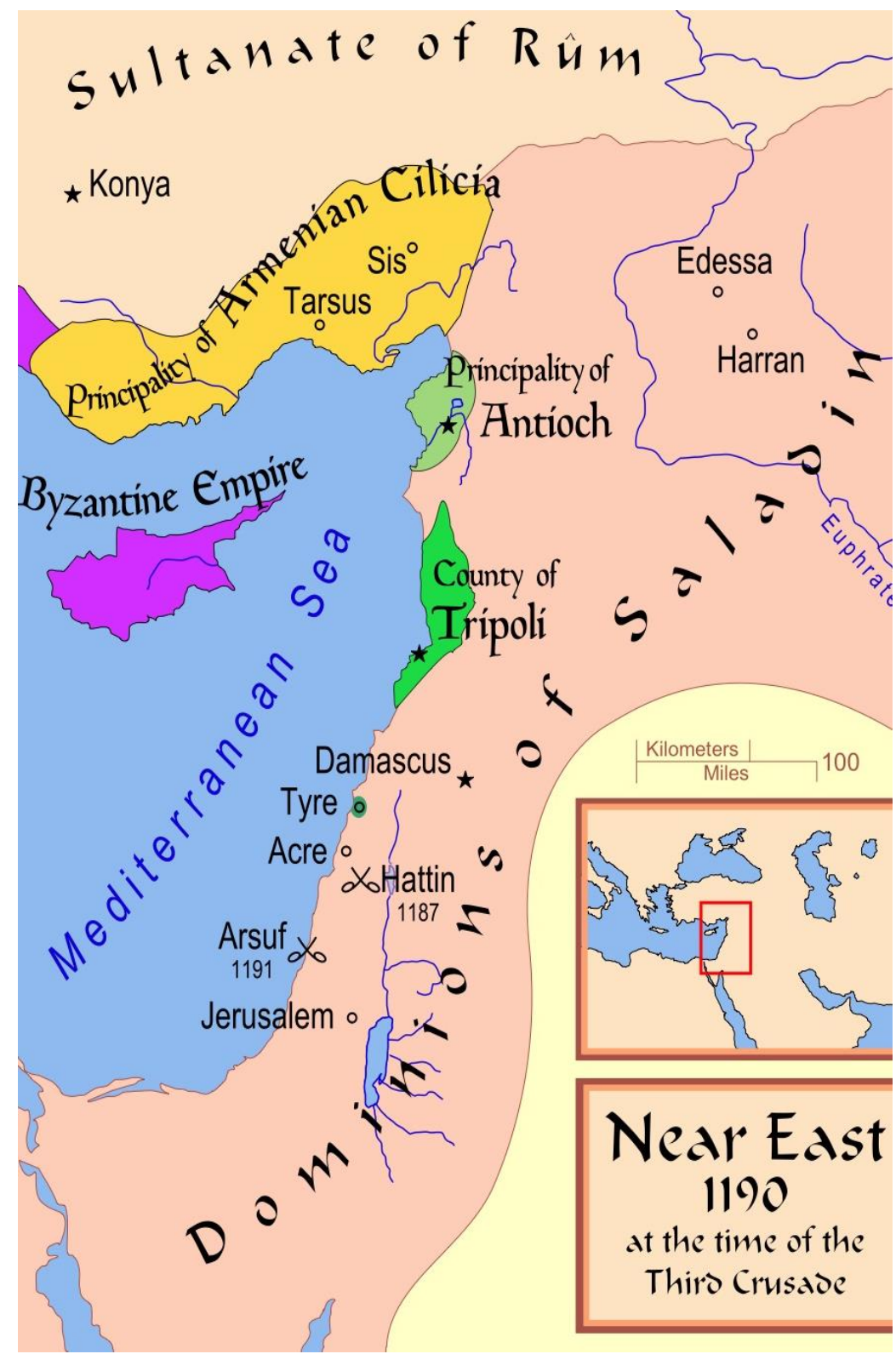

Figure 1. Map of Near East in 1190 at the time of the Third Crusade. 
Figure 2 shows the march to the south of the two armies. It should be noted that King Richard's troops marched along the seashore, whereas the Saladin militia pursued them closely some five to ten kilometers inland, launching sporadic attacks along the route (marked by green arrows). Richard's strategy was smart, since by following the seashore, he prevented attacks by the Muslims on two fronts. Moreover, and most importantly, he had given orders to a fleet to follow his army, so that every day they could obtain a fresh supply of food and fresh water. The fleet also had another important role: it acted as a traveling hospital taking aboard wounded soldiers, where they could be cured by physicians. The final confrontation between the two armies took place in a village called Arsuf (today known as Apollonia, a site some 10 miles from present-day Tel Aviv).

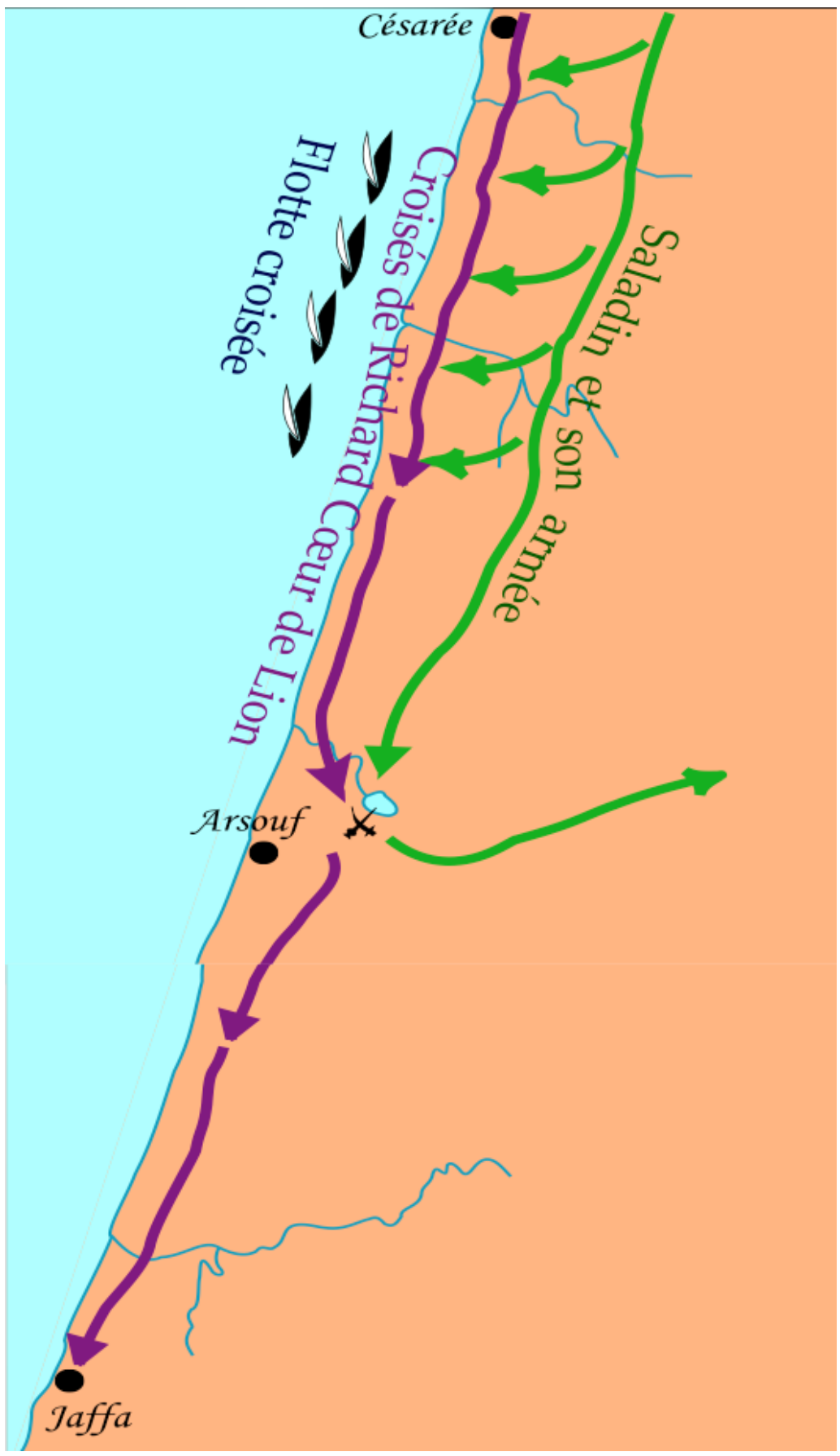

Figure 2. Scheme of the march of King Richard's troops towards Jaffa, followed by his fleet and the pursuit of Saladin's army. 
Figure 3 is an aerial view of the ruins of the Crusader castle in Arsuf, as it is standing today. The castle is perched on a cliff overlooking a ravine directly on the seashore. The site had been abandoned centuries ago, and the castle has never been restored. The locality is in an empty land with no modern settlements in the vicinity.

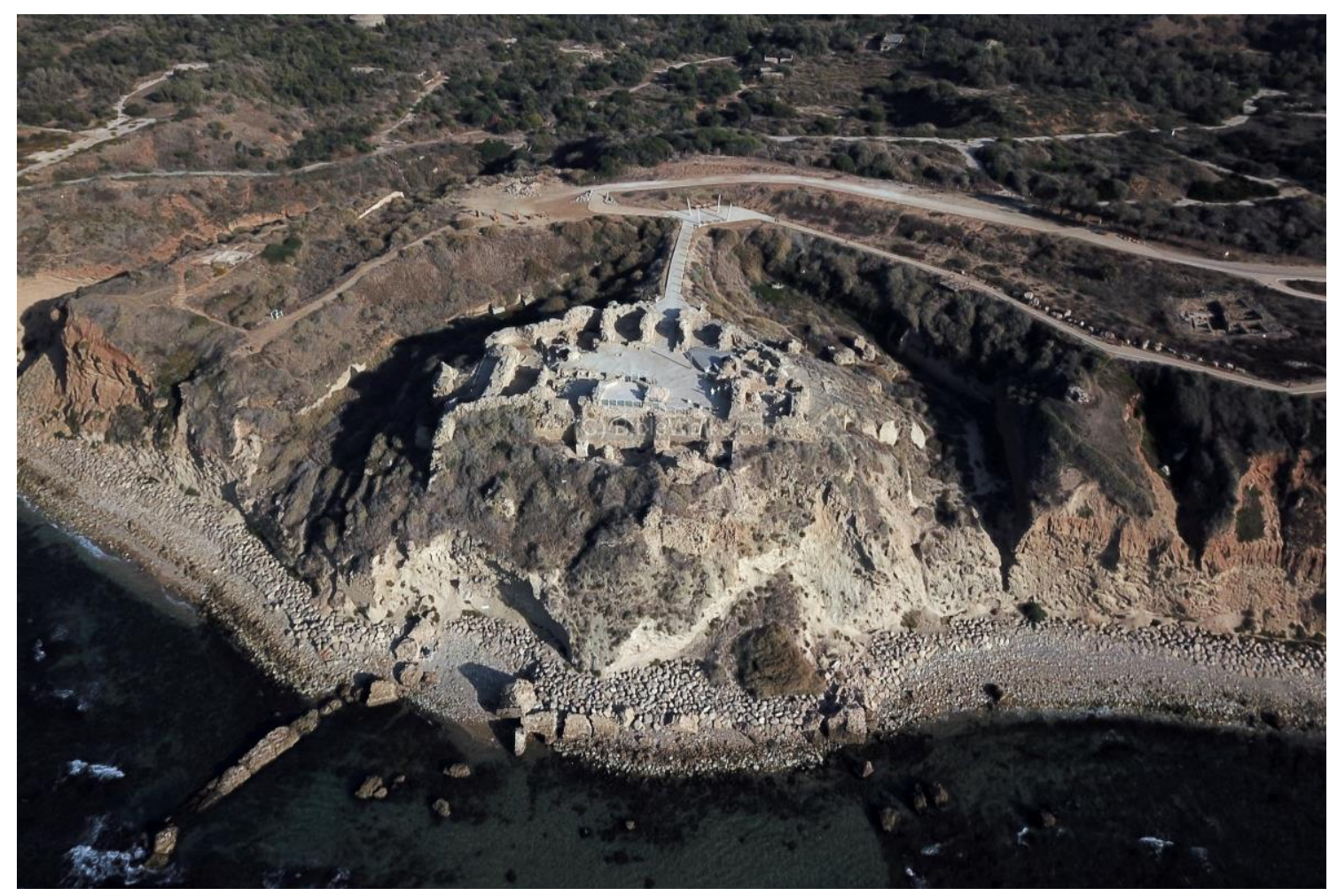

Figure 3. Aerial view of the ruins of Arsuf castle (today Apollonia).

At the feet of the castle, close to the seashore, is the site which we excavated in search of pottery and fragments belonging to the epoch of the Third Crusade. We were led by experts to the archaeological horizon of this crusade, so we know for certain that the pottery we unearthed belongs to this period. Figure 4 shows a small part of the catch of pottery shards we recovered. The differences in manufacturing between the Crusader and Muslim pottery allowed us to sort out the two types of pottery. We used [15-21], for the selection and identification of Crusader and Muslim pottery. Additionally, we gathered information from public exhibitions in Israeli museums for identification of pottery to each period. In any event, in order to show, in better detail, the two types of pottery identified, we provide 12 photographs of Ayyubid and Crusader pottery fragments in two supplementary documents, with the understanding that these are just a small part of the 194 total samples examined. Sand and traces of earth were removed with fine brushes. After this cleaning treatment, we applied several EVA diskettes to the pottery surface and allowed the contact to continue for a minimum of two hours up to a few days, when needed (extraction of food remnants buried within the grains of the pottery turned out to be a lengthy process). Below follows the presentation of the food analysis of the two confronting armies. It should be noted that in all tables, only the proteins identified with a minimum of three peptides are listed. Moreover, in quite a few cases, proteins were identified with up to five peptides. Additionally, in some cases, identifications were obtained with very long peptide sequences. For example, in the case of cytochrome c oxidase subunit 1 (Table 2), peptide No. 2 contains a string of 45 amino acids. 


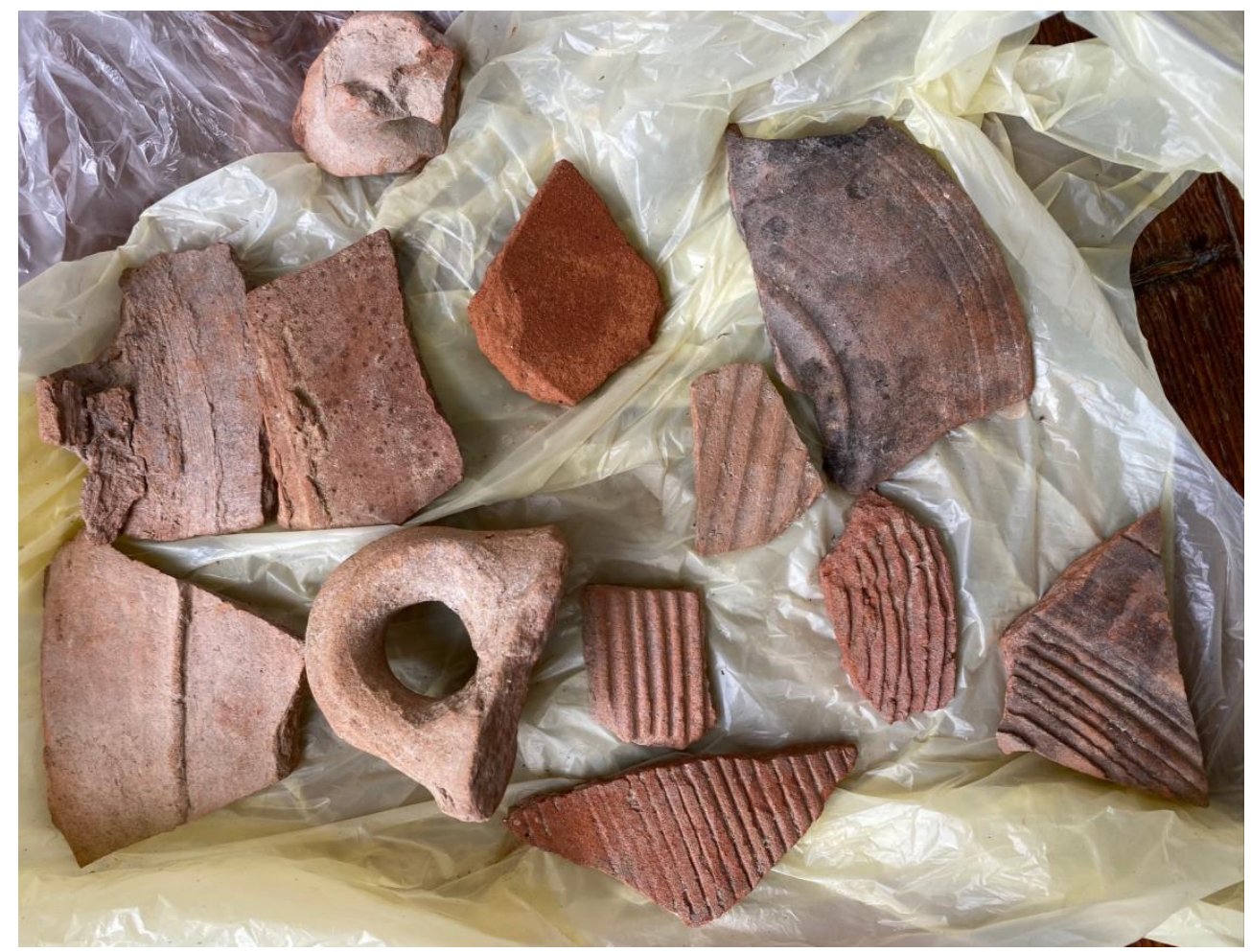

Figure 4. Part of the pottery shards dug out from the Arsuf archaeological site.

\subsection{A Clue on the Crusader Diet}

Table 1 lists a series of fragments of goat milk proteins, while Table 2 provides a number of pig proteins. Table 3 displays the identified grape proteins, indicating the fact that the Crusaders also drunk wine, a beverage strictly forbidden among Muslims, as well as, of course, pig meat. Interestingly, we also found a few proteins from olives (Table 4), suggesting that the Crusaders also ate this fruit, and that they supplemented their diet with honey, as shown from the few protein fragments listed in Table 5. 
Table 1. Fragments of goat milk proteins.

\begin{tabular}{|c|c|c|c|c|c|}
\hline $\begin{array}{l}\text { Accession } \\
\text { Numbers }\end{array}$ & Protein Name & $\begin{array}{l}\text { Mascot } \\
\text { Score }\end{array}$ & Mr & Sequences & $\begin{array}{c}\text { No. } \\
\text { Peptides }\end{array}$ \\
\hline P02670 & Kappa-CN & 225 & 21,441 & $\begin{array}{l}\text { (1) MMKSFFLVVTILALTLPFLGAQEQNQE- } \\
\text { QPICCEK } \\
\text { (2) MAIPPKKDQDK } \\
\text { (3) LSRYPSYG LNYYQQRPVA LINNQFLPYP } \\
\text { YYAKPVAVR }\end{array}$ & 3 \\
\hline P02756 & $\begin{array}{c}\text { Beta- } \\
\text { lactoglobulin }\end{array}$ & 341 & 19,976 & $\begin{array}{l}\text { (1) LEKFDKALKA LPMHIR } \\
\text { (2) LLFCMENSAEPEQSLACQCLVRTPEVDK } \\
\text { (3) LACGIQAIIVTQTMKGLDIQK }\end{array}$ & 3 \\
\hline A0A5K6WAG1 & Kappa-casein & 764 & 21,455 & $\begin{array}{l}\text { (1) VALINNQFLPYPYYAKPVAVR } \\
\text { (2) VPAKSCQDQPTTLAR } \\
\text { (3) QEQNQEQPICCEKDERFFDDKIAK } \\
\text { (4) QPTTLARHPHPHLSFMAIP PK }\end{array}$ & 4 \\
\hline P33048 & Beta-casein & 290 & 24,865 & $\begin{array}{l}\text { (1) LGPVR } \\
\text { (2) LQPEIMGVPKVKETMVPK } \\
\text { HKEMPFPKYPVEPFTESQSL TLTDVEK } \\
\text { (3) MFPPQSVLSLSQPKVLPVPQK } \\
\text { (4) QPEIMGVPKVK }\end{array}$ & 4 \\
\hline P85295 & Albumin & 192 & 10,055 & $\begin{array}{l}\text { (1) DTHKS } \\
\text { (2) DLGRHPEYAVS } \\
\text { (3) VSVLLR } \\
\text { (4) VRXXXKAPQVSTPTLVEISR } \\
\text { (5) QTALVELLK }\end{array}$ & 5 \\
\hline W5VVI0 & Cathelicidin-1 & 365 & 9799 & $\begin{array}{l}\text { (1) DITCNNHQS } \\
\text { (2) FKENGLLKRCEGT VTLDQVR } \\
\text { (3) QCDFKENGLLK }\end{array}$ & 3 \\
\hline P18626 & $\begin{array}{l}\text { Alpha-S1- } \\
\text { casein }\end{array}$ & 269 & 24,290 & $\begin{array}{l}\text { (1) MEDAKQMKAGSS SSSEEIVPNSAEQK } \\
\text { (2) LLRLKKYNVPQLEIVPKS AEEQLHSMK } \\
\text { (3) MKAGSSSSSEEIVPNS AEQKYIQK }\end{array}$ & 3 \\
\hline P33049 & $\begin{array}{l}\text { Alpha-S2- } \\
\text { casein }\end{array}$ & 199 & 26,389 & $\begin{array}{l}\text { (1) MKFFIFTCLLAVALAK } \\
\text { (2) MAIHPRKEK } \\
\text { (3) LNPWDQVK } \\
\text { (4) LTEEEKNRLNFLKKISQYYQK }\end{array}$ & 4 \\
\hline
\end{tabular}


Table 2. Fragments of pig proteins.

\begin{tabular}{|c|c|c|c|c|c|}
\hline $\begin{array}{l}\text { Accession } \\
\text { Numbers }\end{array}$ & Protein Name & $\begin{array}{l}\text { Mascot } \\
\text { Score }\end{array}$ & Mr & Sequences & $\begin{array}{c}\text { No. } \\
\text { Peptides }\end{array}$ \\
\hline P16293 & $\begin{array}{l}\text { Coagulation } \\
\text { factor IX }\end{array}$ & 342 & 45,516 & $\begin{array}{l}\text { (1) MDYENSTEVEPILDSL } \\
\text { TESNQSSDDFIRIVGGENAK } \\
\text { (2) QYLKVPLVDRATCLR STK } \\
\text { (3) FSNMDYENSTEVEPILDSLTESNQSSDDFIR }\end{array}$ & 3 \\
\hline P24964 & Cytochrome b & 201 & 42,782 & $\begin{array}{l}\text { (1) LHANGASMFFICLFIHVGR } \\
\text { (2) LILMPMLHTSK } \\
\text { (3) MFFICLFIHVGR }\end{array}$ & 3 \\
\hline O79876 & $\begin{array}{l}\text { cytochrome c } \\
\text { oxidase } \\
\text { subunit } 1\end{array}$ & 408 & 56,958 & $\begin{array}{l}\text { (1) LYLLFGAWAGMVGTALSLLIR } \\
\text { (2) QIYNVIVTAHAFVMIFFMV } \\
\text { MPIMIGGFGNWLVPLMIGAP DMAFPR } \\
\text { (3) LVPLMIGAPDMAFPR }\end{array}$ & 3 \\
\hline P02189 & Myoglobin & 230 & 17,085 & $\begin{array}{l}\text { (1) LSDGEWQLVLNVWGKVEA } \\
\text { DVAGHGQEVLIR } \\
\text { (2) LKKHGNTVLTALGGILKKK } \\
\text { (3) LTALGGILKKKGHHEAELTPL AQSHATK }\end{array}$ & 3 \\
\hline Q29548 & $\begin{array}{l}\text { Beta- } \\
\text { hexosaminidase } \\
\text { subunit beta }\end{array}$ & 542 & 61,050 & $\begin{array}{l}\text { (1) LQVHVESECDTFPSISSNESYVLHVK } \\
\text { (2) QFMQEK } \\
\text { (3) QSINFGVLSSK }\end{array}$ & 3 \\
\hline Q29016 & $\begin{array}{l}\text { Acrosin- } \\
\text { binding } \\
\text { protein }\end{array}$ & 213 & 60,827 & $\begin{array}{l}\text { (1) MRQLAAGSLL SLLKVLLLPL } \\
\text { APAPAQDANSASTPGSPLSPTEYER } \\
\text { (2) LNNNVEELLQSSLSLGGQE QGQEHK } \\
\text { (3) QSEFVSSNPFSFTPRVRE } \\
\text { VESTPMMMENIQELIR } \\
\text { (4) VASWLQTEFLSFQDGDFPT } \\
\text { KICDTEYVQYPNYCAFKSQQ CMMR }\end{array}$ & 4 \\
\hline A0A5G2QQE9 & $\begin{array}{l}\text { Collagen type I } \\
\text { alpha } 1 \text { chain }\end{array}$ & 277 & 140,883 & $\begin{array}{l}\text { (1) MGPRGPPGPPGKNGDDG EAGKPGR } \\
\text { (2) QAGVMGFPGPKGAAGEPGK } \\
\text { (3) LPGAKGLTGSPGSPGPDGK }\end{array}$ & 3 \\
\hline Q29218 & $\begin{array}{l}\text { Keratin, type I } \\
\text { cytoskeletal } 20\end{array}$ & 678 & 12,528 & $\begin{array}{l}\text { (1) QIQDLRNQIRDAQLQNARCV } \\
\text { LQIDNAKLAAEDFRLK } \\
\text { (2) MTMKNLNDRLASYLEK } \\
\text { (3) QSNSKFELQIK }\end{array}$ & 3 \\
\hline
\end{tabular}


Table 3. Fragments of grape proteins.

\begin{tabular}{|c|c|c|c|c|c|}
\hline $\begin{array}{l}\text { Accession } \\
\text { Numbers }\end{array}$ & Protein Name & $\begin{array}{c}\text { Mascot } \\
\text { Score }\end{array}$ & $\mathrm{Mr}$ & Sequences & $\begin{array}{c}\text { No. } \\
\text { Peptides }\end{array}$ \\
\hline Q6PWU2 & $\begin{array}{l}(-) \text {-alpha- } \\
\text { terpineol } \\
\text { synthase }\end{array}$ & 590 & 68,883 & $\begin{array}{l}\text { (1) MALSMLSSIP NLITHTRLPIIIK } \\
\text { (2) MEQARDFAHRHLGKGLEQN } \\
\text { IDQNLAIEVK } \\
\text { (3) MVQATHQEDLRHMSSWWSSTRLGEK }\end{array}$ & 3 \\
\hline A5C7X2 & $\begin{array}{c}\text { Cytochrome } \\
\text { P450 CYP76Y2 }\end{array}$ & 482 & 55,742 & $\begin{array}{l}\text { (1) MPLILCFFLLQFLRPSSHATKLPPGPT- } \\
\text { GLPILGSLLEIGK } \\
\text { (2) MFRRFDLLGVK } \\
\text { (3) MQEQCGATLKK } \\
\text { (4) MEGAGKFNISDYFPMFRRFDLLGVKRDTF- } \\
\text { SCYK }\end{array}$ & 4 \\
\hline Q8S4W7 & $\begin{array}{c}\text { DELLA protein } \\
\text { GAI1 }\end{array}$ & 673 & 64,866 & $\begin{array}{l}\text { (1) MKREYHHPHHPTCSTSPTGKGK } \\
\text { (2) MWDADPQQDAGMDELLAVLGYNVK } \\
\text { (3) VAVNSVFELHSLLARPGGER } \\
\text { (4) VGWKLAQLAETIHVEFEYR }\end{array}$ & 4 \\
\hline A8VPW4 & $\begin{array}{l}\text { MYBC2-L1 } \\
\text { protein }\end{array}$ & 230 & 25,255 & $\begin{array}{l}\text { (1) VKNYWNSHLRRKLINMGIDPNNHRLSH- } \\
\text { NFPR } \\
\text { (2) VKSVGDNDQTSDAGS CLDDNR } \\
\text { (3) QDTNKGAWSKQEDQKLIDYIRK }\end{array}$ & 3 \\
\hline
\end{tabular}


Table 4. Fragments of olive proteins.

\begin{tabular}{|c|c|c|c|c|c|}
\hline $\begin{array}{l}\text { Accession } \\
\text { Numbers }\end{array}$ & Protein Name & $\begin{array}{c}\text { Mascot } \\
\text { Score }\end{array}$ & Mr & Sequences & $\begin{array}{c}\text { No. } \\
\text { Peptides }\end{array}$ \\
\hline E3SU11 & $\begin{array}{c}\text { Thaumatin- } \\
\text { like } \\
\text { protein }\end{array}$ & 458 & 24,727 & $\begin{array}{l}\text { (1) VSLWAITFFAYTHAATFDIVNQC- } \\
\text { TYTVWAAASPGGGR } \\
\text { (2) VFNTNEYCCTNGPGSCGPTPLSR } \\
\text { (3) FALNQPNNLDFVDISNVDGFNIPLEFSPT- } \\
\text { TNVCR }\end{array}$ & 3 \\
\hline A0A1D6ZNQ5 & $\begin{array}{l}\text { Acyl-[acyl- } \\
\text { carrier-protein] } \\
\text { desaturase }\end{array}$ & 511 & 44,622 & $\begin{array}{l}\text { (1) VAQRLGVYTAKDYADILEFLVGRWDVEKLT- } \\
\text { GLSGEGR } \\
\text { (2) FQERATFISHGNTAR } \\
\text { (3) VEKLFEIDPDGTVLALADMMR } \\
\text { (4) VYTAKDYADILEFLVGRWDVEKLTGLSGEGR }\end{array}$ & 4 \\
\hline E3NYV3 & Lipoxygenase & 297 & 101,717 & $\begin{array}{l}\text { (1) VDKSYLPSNTPSGLKI } \\
\text { YREKELQILRGDGTGERKTFER } \\
\text { (2) VELPKQKSTGFLANIIPR } \\
\text { (3) VEKNVLLFETPQLYER } \\
\text { (4) VSHWLR } \\
\text { (5) VIATNRQLSAMHPVYKLHPHLR }\end{array}$ & 5 \\
\hline
\end{tabular}

Table 5. Fragments of honey proteins.

\begin{tabular}{cccll}
\hline $\begin{array}{c}\text { Accession } \\
\text { Numbers }\end{array}$ & Protein Name & $\begin{array}{c}\text { Mascot } \\
\text { Score }\end{array}$ & Mr & \multicolumn{1}{c}{$\begin{array}{c}\text { Sequences } \\
\text { Peptides }\end{array}$} \\
\hline P01501 & Melittin & 342 & 7585 & $\begin{array}{l}\text { (1) VLTTGLPALISWIKR } \\
\text { (2) MVVYISYIYAAPEPEPAPEPEAEADAEAD- } \\
\text { PEAGIGAVLK } \\
\text { (3) LTTGLPALISWIKR }\end{array}$ \\
\hline O18330 & $\begin{array}{l}\text { Major royal } \\
\text { jelly protein 1 }\end{array}$ & 211 & $\begin{array}{l}\text { (1) VSKSGVLFFGLVGDSLGCWNEHRTLER } \\
\text { (2) VCQGTTGNILR }\end{array}$ \\
& 48,886 & $\begin{array}{l}\text { (3) LPILHEWKFFDYDFGSDER } \\
\text { (4) LSPMTNNLYYSPVASTSLYYVNTEQFR }\end{array}$ \\
\hline
\end{tabular}

\subsection{A Clue on the Saracen Diet}

It would appear that the main ingredients in the Muslim diet consisted mostly of cereals. Table 6 lists fragments of common wheat proteins, while Table 7 displays fragments of Triticum durum, and Table 8 catalogs Hordeum vulgare proteins. Table 9 codifies some fragments of sheep milk proteins. 
Table 6. Fragments of common wheat proteins.

\begin{tabular}{|c|c|c|c|c|c|}
\hline $\begin{array}{l}\text { Accession } \\
\text { Numbers }\end{array}$ & Protein Name & $\begin{array}{l}\text { Mascot } \\
\text { Score }\end{array}$ & Mr & Sequences & $\begin{array}{c}\text { No. } \\
\text { Peptides }\end{array}$ \\
\hline P17314 & $\begin{array}{l}\text { Alpha- } \\
\text { amylase/trypsin } \\
\text { inhibitor CM3 }\end{array}$ & 123 & 18,221 & $\begin{array}{l}\text { (1) MACKSSCSLLLLAAVLLSVLAAASAS- } \\
\text { GSCVPGVAFR } \\
\text { (2) LPEWMTSASIYSPGKPYLAKLYCCQE- } \\
\text { LAEISQQCR } \\
\text { (3) LYCCQELAEISQQCRCEALR }\end{array}$ & 3 \\
\hline Q10464 & Puroindoline-B & 221 & 16,792 & $\begin{array}{l}\text { (1) LFLLALLALVASTTFAQYSEVGG- } \\
\text { WYNEVGGGGGSQQCPQERPK } \\
\text { (2) QERPK } \\
\text { (3) VIQGRLG GFLGIWRGEVFKQLQR } \\
\text { (4) LFLLALLALVASTTFAQYSEVGGWYNE } \\
\text { VGGGGGSQQCPQER }\end{array}$ & 4 \\
\hline P82900 & $\begin{array}{l}\text { Non-specific } \\
\text { lipid-transfer } \\
\text { protein } 2 \mathrm{G}\end{array}$ & 291 & 9832 & $\begin{array}{l}\text { (1) QGCFCQYAKD } \\
\text { (2) LRAQQGCFCQYAKPTYGQYIR } \\
\text { (3) QYAKDPTYGQYIR }\end{array}$ & 3 \\
\hline P01544 & $\begin{array}{l}\text { Alpha-1- } \\
\text { purothionin }\end{array}$ & 652 & 13,526 & $\begin{array}{l}\text { (1) LALESNSDEPDTIEYCN } \\
\text { (2) LGCRLCRARGAQKLCAGVCRCK } \\
\text { (3) QLQVEGKSCCRSTLGRNCYNLCR }\end{array}$ & 3 \\
\hline P10388 & $\begin{array}{l}\text { Glutenin high } \\
\text { molecular mass } \\
\text { subunit }\end{array}$ & 299 & 90,293 & $\begin{array}{l}\text { (1) QVSYYPGQASPQR } \\
\text { (2) QLRDISPECHPVVVSPVAGQYEQQIVPK } \\
\text { (3) LQQPAQGQQGQQLAQGQQGQQ- } \\
\text { PAQVQQGQR }\end{array}$ & 3 \\
\hline A0A3B6C437 & Beta-amylase & 331 & 67,919 & $\begin{array}{l}\text { (1) LEEDFRAAATDAGHPEWELPDDAGEYN- } \\
\text { DAPDDTR } \\
\text { (2) LAAKVSGIHWWYR } \\
\text { (3) LDGRDGYRPIAR } \\
\text { (4) LARHDGAVLNFTCAEMR }\end{array}$ & 4 \\
\hline P01543 & $\begin{array}{l}\text { Purothionin } \\
\text { A-1 }\end{array}$ & 441 & 14,625 & $\begin{array}{l}\text { (1) LCANVCR } \\
\text { (2) LSCPKDPKLVLESNSDEPDTMEYCNLGCR } \\
\text { (3) LVLEQVQVEGKSCCK } \\
\text { (4) LVLESNSD EPDTMEYCNLGCR }\end{array}$ & 4 \\
\hline P17314 & $\begin{array}{l}\text { Alpha- } \\
\text { amylase/trypsin } \\
\text { inhibitor }\end{array}$ & 226 & 18,221 & $\begin{array}{l}\text { (1) LPEWMTSASIYSPGKPYLAK } \\
\text { (2) LIDLPGCPREMQWDFVR } \\
\text { (3) LPVPSQPVDPRSGNVGES- } \\
\text { GLIDLPGCPREMQWDFVR }\end{array}$ & 3 \\
\hline P83207 & $\begin{array}{l}\text { Chymotrypsin } \\
\text { inhibitor }\end{array}$ & 270 & 12,944 & $\begin{array}{l}\text { (1) QPPLAPRCPTEVKR } \\
\text { (2) LQGCHYYVTSQTCGFVPLLPIEVMK } \\
\text { (3) QGCHYYVTSQTCGFVPLLPIEVM KDRCCR }\end{array}$ & 3 \\
\hline P93692 & Serpin-Z2B & 378 & 42,981 & $\begin{array}{l}\text { (1) QYIS SSDGLKVLKLPYKQGGDK } \\
\text { (2) LIKDILPAGSIDNTTR } \\
\text { (3) QLAATLGEGEVEGLHALAE- } \\
\text { QVVQFVLADASNIGGPR }\end{array}$ & 3 \\
\hline P01084 & $\begin{array}{l}\text { Alpha-amylase } \\
\text { inhibitor }\end{array}$ & 497 & 13,185 & $\begin{array}{l}\text { (1) VPALPGCRPLKLQCNG SQVPEAVLR } \\
\text { (2) LYSMLDSMYK } \\
\text { (3) QAFQVPALPGCRPLLKLQCNGSQVPEAVLR }\end{array}$ & 3 \\
\hline
\end{tabular}


Table 7. Fragments of Triticum durum proteins.

\begin{tabular}{|c|c|c|c|c|c|}
\hline $\begin{array}{l}\text { Accession } \\
\text { Numbers }\end{array}$ & Protein Name & $\begin{array}{l}\text { Mascot } \\
\text { Score }\end{array}$ & $\mathrm{Mr}$ & Sequences & $\begin{array}{c}\text { No. } \\
\text { Peptides }\end{array}$ \\
\hline A0A446NJU5 & Ribokinase & 234 & 36,611 & $\begin{array}{l}\text { (1) LEARLRLPLAGPTPATAFLSGSNPK } \\
\text { (2) LDLIRQAGVLLLQR } \\
\text { (3) QNSIIIVGGANMEGWAPEVDQEDLDLIR }\end{array}$ & 3 \\
\hline A0A446KRB8 & UMP-CMP kinase & 211 & 26,949 & $\begin{array}{l}\text { (1) LIDGFPRNE ENRAAFENVTK } \\
\text { (2) LIKTTIFVFPTIRIVLQGR } \\
\text { (3) LMFGLCILIK }\end{array}$ & 3 \\
\hline A0A446WFI0 & $\begin{array}{l}\text { NAD }(\mathrm{P}) \mathrm{H} \text {-hydrate } \\
\text { epimerase }\end{array}$ & 231 & 53,127 & $\begin{array}{l}\text { (1) LIICGPGNNGGDGLVAAR } \\
\text { (2) LTAPKLCAKKFTGPHHFLGGRFVPPPISSK } \\
\text { (3) LTTVNKAGKPSSRMVLLKGVDK }\end{array}$ & 3 \\
\hline A0A446K973 & $\begin{array}{c}\text { Flap endonuclease } \\
1\end{array}$ & 402 & 42,744 & $\begin{array}{l}\text { (1) LQGMFSRTIRLLEAGI } \\
\text { KPVYVFDGKPPEMKK } \\
\text { (2) LENINKDKYQIPEDWPYQEARRM- } \\
\text { FKEPDVTLDIPELK } \\
\text { (3) QHGSIEGILENINKDKYQ IPEDWPYQEAR }\end{array}$ & 3 \\
\hline A0A446X1P5 & $\begin{array}{l}\text { ATP-dependent 6- } \\
\text { phosphofructokinase }\end{array}$ & 478 & 50,586 & $\begin{array}{l}\text { (1) LKVAVAGIPKTIDNDIPVIDK } \\
\text { (2) LAHSVVHGAMAGYTGFTVGQVNGR } \\
\text { (3) LSSTNQPSFLSKQDVDDAVEDER }\end{array}$ & 3 \\
\hline
\end{tabular}


Table 8. Fragments of Hordeum vulgare proteins.

\begin{tabular}{|c|c|c|c|c|c|}
\hline $\begin{array}{l}\text { Accession } \\
\text { Numbers }\end{array}$ & Protein Name & $\begin{array}{l}\text { Mascot } \\
\text { Score }\end{array}$ & $\mathrm{Mr}$ & Sequences & $\begin{array}{c}\text { No. } \\
\text { Peptides }\end{array}$ \\
\hline P82993 & Beta-amylase & 308 & 59,639 & $\begin{array}{l}\text { (1) VNIPIPQWVRDVGTRDPDIFYTDGHGTR } \\
\text { (2) MEVNVK } \\
\text { (3) MLPLDAVSVNNRFEKGDELRAQLRK } \\
\text { (4) QAMSAPEELVQQVLSAGWR }\end{array}$ & 4 \\
\hline P45850 & $\begin{array}{c}\text { Oxalate } \\
\text { oxidase } 1\end{array}$ & 211 & 21,203 & $\begin{array}{l}\text { (1) VSFNSQNPGIVFVPLTLFGSDPPIPTPVLTKALR } \\
\text { (2) VAEWPGTNTLGVSMNRVDFAPGGTNPPHIHPR } \\
\text { (3) QNPGIVFVPLTLFGSDPPIPTPVLTKALR }\end{array}$ & 3 \\
\hline P27337 & Peroxidase 1 & 201 & 32,976 & $\begin{array}{l}\text { (1) VSCADILTVAARDSVVALGGPSWTVPLGRR } \\
\text { (2) VQGCDASVLLSGMEQNAIPNAGSLR } \\
\text { (3) QGQIRLSCSR }\end{array}$ & 3 \\
\hline P55307 & $\begin{array}{l}\text { Catalase } \\
\text { isozyme } 1\end{array}$ & 309 & 56,586 & $\begin{array}{l}\text { (1) VRFSTVVHERGSPETLRDPRGFAVKFYTR } \\
\text { (2) VHAFKPSPKTNMQENWRVVDFFSHH- } \\
\text { PESLHMFTFLF DDVGIPLNYR } \\
\text { (3) VNAPKCAHHNNHHDGLMNFIHR } \\
\text { (4) VSQLTCADFLR }\end{array}$ & 4 \\
\hline F2CTM5 & Ribokinase & 266 & 37,073 & $\begin{array}{l}\text { (1) VEVNRLPLVGETVAASAGHSLAGGKGAN- } \\
\text { QAACGGR } \\
\text { (2) VALVEGKPKKECMRFAAAAASLCVRVK- } \\
\text { GAIPSMPDR } \\
\text { (3) VPVLDAGGMDAPVPRELLELVDIFSPNETELAR }\end{array}$ & 3 \\
\hline
\end{tabular}


Table 9. Fragments of sheep milk proteins.

\begin{tabular}{|c|c|c|c|c|c|}
\hline $\begin{array}{l}\text { Accession } \\
\text { Numbers }\end{array}$ & Protein Name & $\begin{array}{l}\text { Mascot } \\
\text { Score }\end{array}$ & $\mathrm{Mr}$ & Sequences & $\begin{array}{c}\text { No. } \\
\text { Peptides }\end{array}$ \\
\hline P21814 & $\begin{array}{l}\text { Uterine milk } \\
\text { protein }\end{array}$ & 265 & 49,223 & $\begin{array}{l}\text { (1) QPNLTQKEDFF LNDKTKVQVDMMRK } \\
\text { (2) VHLGRELVKQKQLR } \\
\text { (3) QIRKLQKMDIQMIDFSDTEKAKKAISHH- } \\
\text { VAEKTHTKIR }\end{array}$ & 3 \\
\hline R9WQI9 & Prolactin & 390 & 25,778 & $\begin{array}{l}\text { (1) VLMSLILGLLRSWNDPLYHLVTEVR } \\
\text { (2) FGQVIPGAKETEPYPVW SGLPSLQTKDEDAR } \\
\text { (3) VMVSHYIHNLSSEMFNEFDKR }\end{array}$ & 3 \\
\hline C7DLN1 & $\begin{array}{l}\text { Fatty acid } \\
\text { synthase }\end{array}$ & 241 & 9232 & $\begin{array}{l}\text { (1) VEDAFRYMAQGKHIGKVVIQVREEER } \\
\text { (2) VTFHGILLDALFEENSTMWQEVSSLLKA- } \\
\text { GIREGVVQPLKR } \\
\text { (3) QVEDAFRYMAQGKHIGK VVIQVR }\end{array}$ & 3 \\
\hline P04654 & $\begin{array}{l}\text { Alpha-s2- } \\
\text { casein }\end{array}$ & 322 & 26,332 & $\begin{array}{l}\text { (1) VFTKKTKLTEEEKNR } \\
\text { (2) MKFFIFTCLLAVALAKHKMEHVSSSEEPIN- } \\
\text { ISQEIYKQEK } \\
\text { (3) QKFPQYLQYLYQGPIVLNPWDQVKR }\end{array}$ & 3 \\
\hline
\end{tabular}

\subsection{A Common Foodstuff to Both Armies}

Interestingly, in both types of pottery, we found traces of another type of food consumed by both armies, namely, sheep meat. In the case of Saladin's troupes, sheep flocks were quite common in Palestinian land, and for Crusaders, sheep would likely come from the fertile planes of Cyprus. It is here underlined that these are our main findings and cannot possibly cover the entire range of aliments consumed by both armies. For instance, surely the Crusaders must have consumed cereals as well, at least in the form of bread. However, in this particular case, remnants of bread were not so traceable in their pottery. Table 10 lists the sheep proteins detected in pottery from both armies. 
Table 10. Fragments of sheep proteins.

\begin{tabular}{|c|c|c|c|c|c|}
\hline $\begin{array}{l}\text { Accession } \\
\text { Numbers }\end{array}$ & Protein Name & $\begin{array}{c}\text { Mascot } \\
\text { Score }\end{array}$ & Mr & Sequences & $\begin{array}{c}\text { No. } \\
\text { Peptides }\end{array}$ \\
\hline Q29524 & $\begin{array}{l}\text { Lipoprotein } \\
\text { lipase }\end{array}$ & 207 & 53,588 & $\begin{array}{l}\text { (1) VIAERGLGDVDQLVKCSHERSVHLFIDSLL- } \\
\text { NEENPSKAYR } \\
\text { (2) VRAKRSSKMYLKTR } \\
\text { (3) VIFVKCHDKSLNR }\end{array}$ & 3 \\
\hline P67930 & Somatotropin & 386 & 24,631 & $\begin{array}{l}\text { (1) VTPRAGQILKQTYDKFDTNMR } \\
\text { (2) VFTNSLVFGTSDR } \\
\text { (3) QILKQTYDKFDTNMR }\end{array}$ & 3 \\
\hline Q8SQG7 & $\begin{array}{l}\text { Hyaluronidase- } \\
2\end{array}$ & 265 & 54,229 & $\begin{array}{l}\text { (1) VHLEMLKGHVEHYIRTQEPAGLAVIDWEDWR } \\
\text { (2) VYLEETLASSTHGRNFVSFRVQEALR } \\
\text { (3) VADVHHANHALPVYVFTR } \\
\text { (4) MDLISTIGES AALGAAGVIL } \\
\text { WGDAGFTTSNETCRRLK } \\
\text { (5) VASHHPDWPPERIVKEAQYEFEFAAR }\end{array}$ & 5 \\
\hline P56591 & $\begin{array}{l}\text { Cytochrome } \\
\text { P450 1A1 }\end{array}$ & 497 & 59,230 & $\begin{array}{l}\text { (1) VANVICAICFGRR } \\
\text { (2) VFVNQWQINHDQKLWEDPSEFRPER } \\
\text { (3) QLPYLEAFILETFRHSSFVPFTIPHSTTR }\end{array}$ & 3 \\
\hline P43477 & Dipeptidase 1 & 567 & 45,096 & $\begin{array}{l}\text { (1) VAVCTADQFRDNAVR } \\
\text { (2) VSKYPDLVAELLRRQWTEEEVRGALAENLLR } \\
\text { (3) QAPGEEPIPLGQLEASCR }\end{array}$ & 3 \\
\hline Q6YNX6 & Calmodulin & 345 & 16,838 & $\begin{array}{l}\text { (1) VDADGNGTIDFPEFLTMMARKMKDT } \\
\text { DSEEEIREAF } \\
\text { (2) VMTNLGEKLTDEEVDEMIR } \\
\text { (3) VDEMIR }\end{array}$ & 3 \\
\hline P02190 & Myoglobin & 522 & & $\begin{array}{l}\text { (1) VLNAWGKVEA DVAGHGQEVL IR } \\
\text { (2) VKYLEFISDAIIHVLHAKHPSDFGADAQGAM- } \\
\text { SKALELFR } \\
\text { (3) VFDKDGNGISAAELR }\end{array}$ & 3 \\
\hline W5P481 & Collagen & 455 & 140,644 & $\begin{array}{l}\text { (1) VWKPVPCQICVCDNGNVLC DDVICDELKD } \\
\text { CPNAKVPTPPR } \\
\text { (2) QDGRPGPPGPPGARGQAGVMGFPGPK } \\
\text { (3) V PGDLGAPGPSGARGER }\end{array}$ & 3 \\
\hline P02446 & Keratins & 387 & & $\begin{array}{l}\text { (1) VRTGPATTICSSDKFCR } \\
\text { (2) VYPDTYVPTCFLLNSSHPTPGLSGINLTTFIQPG- } \\
\text { CENVCEPR } \\
\text { (3) LSGINLTTFIQPGCENVCEPR }\end{array}$ & 3 \\
\hline
\end{tabular}

\section{Discussion}

\subsection{Evaluation of our Extraction Procedure}

Proteomics has been widely applied to detect and identify proteins on paleontological and archaeological artifacts. The widespread success of mass spectrometry in identifying ancient proteins has been, however, mostly limited to bones and other tissues (e.g., dental calculus) [22]. This is because these proteins are shielded and buried within a hydroxyapatite cage that protects them not only from external contamination but also from degradation caused by the environment. In pottery, these aspects are aggravated, first of all, due to the fact that considerably fewer proteins are adsorbed within the grains of ceramics, but also because they are much more exposed to external contaminants from the terrain and to degradation caused by soil bacteria. Yet, in recent years, data have been published demonstrating the possibility of extracting and identifying food residues buried in ancient pottery. Already in 2004, Guasch-Jané et al. [23] showed the identification of wine markers in ancient Egyptian vessels. Later on, Solazzo et al. [24] and Dallongeville et al. [25] produced evidence on the presence of proteins in potsherds and ancient amphorae. The processing of dietary cereals 
was assessed by Hammann et al. [26] in archaeological pottery via the presence of absorbed lipid biomarkers, while Hendy et al. [27] and Tanasi et al. [28] extracted food residues even from prehistoric pottery. A comparison between this last report and our data is worth commenting upon. In order to obtain sufficient material from the food traces remaining in these very ancient vessels, the ceramic fragments were ground using an agate mortar and pestle until an impalpable powder was obtained. The organic material was extracted under two different conditions: in one case at $\mathrm{pH}=2(0.1 \%$ of trifluoroacetic acid and $4 \%$ sodium-dodecyl-sulphate solution, SDS) for $30 \mathrm{~min}$ at $95{ }^{\circ} \mathrm{C}$; in the second case in alkaline reducing conditions, $\mathrm{pH}=8.5$ ( $4 \%$ SDS, $100 \mathrm{mM}$ Tris $/ \mathrm{HCl}$ and $0.1 \mathrm{M}$ dithiothreitol) for $30 \mathrm{~min}$ at $95^{\circ} \mathrm{C}$. Our strategy was completely different. The cleaned pottery fragments were overlaid with humidified EVA diskettes, and extraction was allowed to proceed for up to one week. This is certainly a longer time but leaves the ceramic material intact. Obviously, destruction of samples is allowed in the case of pottery shards, but if one had to go to museums and attempt an extraction on the most valuable items, only our technology would be allowed, of course, since it is non-damaging and non-contaminating.

Among the food remnants we identified, it might sound surprising that there could be traces of pork meat in a Muslim territory where no such animals were tolerated and no such food could be eaten. Yet, historical records [14] explain the mystery: in preparation of the Crusades, the king's functionaries had collected huge quantities of cheese from Essex, dry legumes (mostly peas and broad beans) from Kent and Cambridge and in excess of 14,000 pigs from the counties of Hampshire, Essex and Lincoln. The pigs were slaughtered, chopped to pieces and dried and salted. In addition to that, they hoarded huge amounts of wheat grains (for preparing bread locally while waging war) as well as a large supply of barrels of wine. Therefore, a supply of this food was available to the Crusaders. Were this not enough, the king took care of transportation too: he ordered the construction (and/or acquisition) of 100 ships as well as 14 large "busses" (fishing boats). Additionally, on his way to the Holy Land, King Richard had conquered the island of Cyprus, a precious territory that could supply plenty of foodstuffs to his army.

\subsection{A Closer Survey of the Arsuf Battle}

It was not uncommon during the previous two crusades, as well as in the following ones, that entire garrisons, villages and even fortified towns had to surrender for lack of food and, even more pressing, for lack of water, a critical supply in these territories surrounded by deserts. King Richard was a shrewd leader and was well aware of these problems. That is why, after carrying out the siege and capture of Acre, when moving south to conquer Jerusalem, he decided to march along the coastline while being escorted by an entire fleet, providing the much-needed supply of foodstuffs and negating the possibility of being attacked by the Muslim army on the right side of his marching column.

The confrontation in Arsuf was indeed quite harsh. A vivid account of the skirmishes and final confrontation was provided by Geoffrey de Vinsauf (in Latin prose) in the thirteenth century, shortly after the death of King Richard [29]. We offer here some excerpta as rendered in a more readable English prose by Thomas Bulfinch [30]. Marching order: King Richard, most experienced in military affairs, divided the army into twelve companies, and these again into five divisions, marshalled according to strict military discipline. Therefore, in order to prevent the invasion of Saracens within his marching soldiers, they were "kept together so closely that an apple, if thrown, would not have fallen to the ground without touching a man or a horse". Additionally, King Richard and the Duke of Burgundy, with a chosen retinue of warriors, rode up and down the stretched marching line, narrowly monitoring the chasing Turks as well as their own troops. Here is how the frequent harassing attacks of the Saracens on the Crusaders marching south were conducted. To start with, they were stunned by "military bands" playing "clarions and trumpets; some had horns, others had pipes and timbrels, gongs, cymbals, and other instruments, producing a horrible noise and clamour". Then, the enemy came rushing down, like a torrent, to the attack: "it rained darts; the air was filled with the shower of 
arrows, and the brightness of the sun was obscured by the multitude of missiles, as if it had been darkened by a fall of winter's hail or snow". The distress of Crusaders is narrated with eloquence by Geoffrey de Vinsauf: "In truth our people, so few in number, were so hemmed in by the multitudes of the Saracens, that they had no means of escape, if they tried; neither did they seem to have valour sufficient to withstand so many foes, nay, they were shut in like a flock of sheep in the jaws of wolves, with nothing but the sky above, and the enemy all around them". Yet, when reaching Arsuf and the battle took a violent turn, the deeds of King Richard were so striking that his marksmanship became legendary: "There the king, the fierce, the extraordinary king, cut down the Turks in every direction, and none could escape the force of his arm, for wherever he turned, brandishing his sword, he carved a wide path for himself; and as he advanced he gave repeated strokes with his sword, cutting them down like a reaper with his sickle". At the highest pitch of the battle, Richard's exploits took an even more vehement turn: "the king, mounted on a bay Cyprian steed, which had not its match, bounded forward in the direction of the mountains, and scattered those he met on all sides; for the enemy fled from his sword and gave way, while helmets tottered beneath it, and sparks flew forth from its strokes". One wonders if there is some exaggeration taken from the ballads of King Arthur, and the "chevaliers de la table ronde" may even be from the Chanson de Roland. At the end of the day, the Christians counted seven thousand Saracens slain and only one tenth in their files missing.

\subsection{Evaluation of the Crusades over the Centuries}

All throughout Europe, the Crusades were valued positively for centuries. It cannot be forgotten that Muslims had invaded the south of Europe already during the reign of Charlemagne, an expansion that he was not quite successful in contrasting. In fact, it was only during the reign of Isabelle of Castille that the Moors were evicted from Spain in 1492. During the Renaissance, the epos of the Crusades peaked, and entire poems were composed in their celebration. For instance, Orlando Furioso by Ludovico Ariosto deals, in grand part, with conflicts between the Christian and Muslim worlds. One of the Saracens kings, Rodomonte, during the siege of Paris, manages to climb the ramparts of the city and wreck havoc among the Christians, rudely cutting to pieces the inhabitants much in the same way as King Richard valiantly fought in Arsuf (canto XIV, octets 113-125). La Gerusalemme Liberata by Torquato Tasso should also be mentioned, which is entirely devoted to the Crusades. It starts, in fact, with Godfrey of Bouillon leaving France for Jerusalem and ends (canto XX) with a final battle between the Muslims and the Crusaders, with the victory of the latter army and the liberation of the Holy Sepulchre. It cannot also be forgotten that the Turks kept threatening the borders of Europe for centuries, with continuous clashes that peaked with the Battle of Lepanto (7 October 1571), a tremendous skirmish between the 210 galleons of European forces and the more than 300 vessels of the Muslim fleet. The Christianity victory kept the Muslim world at bay for centuries after.

The first hole in the wall was bored by the two encyclopedists, Diderot and D'Alembert, who stated: "des temps de ténebres assez profondes, \& d'un étourdissement assez grand [... ] pour entraîner une partie du monde dans une malheureuse petite contrée, afin d'en égorger les habitans, \& de s'emparer d'une pointe de rocher qui ne valoit pas une goutte de sang" ("a time of such a deep darkness and of such extreme excitement [ ... ] as to drag a part of the word in an unlucky, small country just to slit the throat to their inhabitants and take over a rocky peak that was not worth a drop of blood") [31]. Imagine if Voltaire would lag behind: "an epidemic folly that lasted more than 200 years, and was distinguished by any possible cruelty, wickedness, intemperance, madness of which the human kind would be capable" [32]. In the nineteenth century, an epoch of romanticism, this criticism was ignored, though. In fact, the Crusaders were shrouded in a mystic halo. The situation was reversed in the twentieth-twenty-first centuries, also due to the fact that it was in this period that most of the books on the Crusades were written [1-14]. For instance, Sir James Cochran Stevenson Runciman [4], author of a classic trilogy on the Crusades, expressed a strong criticism. According to him: "High ideals were besmirched by cruelty and greed, 
enterprise and endurance by a blind and narrow self-righteousness, and the holy war itself was nothing more than a long act of intolerance in the name of God, which is a sin against the holy ghost". He underlined that the Crusades were the last of the barbarian invasions; their disaster was their failure to understand Byzantium. Needless to say, on the Internet, one can find plenty of documents in full support of the Crusades, thus leaving the debate fully open.

\section{Conclusions}

Based on the data here presented, we suggest that the Crusaders' diet (low-carbohydrate, high-protein consumption, as opposed to the Muslims' diet, high in carbohydrates) might have helped them in battle since this diet is more energetic and maintains the body slim and supple. That being said, perhaps King Richard's troop might have anticipated what became popular in this century as the Atkins diet, popularized by this physician in a book published in 1972 [33]. Of course, this is a mere hypothesis and, in any event, does not cancel the very first requirements in battles, namely, shrewdness of leaders, and soldiers' equipment and willingness to fight, all of them being the main ingredients of a victory.

It is not the aim of the present investigation to issue a moral judgment on the Crusades, which we leave to historians. We just want to dedicate our humble work to these two unique, memorable figures, King Richard I and his opponent, the equally noble and shrewd leader, the sultan Salah ad-Din. We are pleased to state that Dante places him in the Canto IV of the Inferno, but in a special place called Limbo (a location of lenience for those who had no access to Christianity). He is placed in a castle of the "Spiriti Magni" (Noble Souls), an inaccessible fortified compound enclosed within seven walls:

Vidi quell Bruto che cacciò Tarquinio,

Lucrezia, Iulia, Marzia e Corniglia;

E solo, in parte, vidi '1 Saladino

(Verses 127-129). Not a bad place to be in!

\section{Post-Scriptum}

We are pleased to mention here a paper by Charlier et al. [34] on the analysis of the embalmed King Richard heart, discovered in a casket buried in the Notre Dame cathedral in Rouen. They found that the heart was wrapped in linen, associated with myrtle, daisy, mint, frankincense, creosote, mercury and lime. They noted, additionally, that the goal of using such preservation materials was not only to allow long-term conservation of the tissues but also a good scent similar to the one of Christ's burial (comparable to the bouquet of sanctity). Additionally, upon a request of one referee, we added a few more references to the poems here quoted $[35,36]$.

Supplementary Materials: The following are available online at https:/ /www.mdpi.com/article/10 .3390/heritage4040188/s1, Figure S1: Ayyubid pottery, Figure S2: Crusaders pottery.

Author Contributions: Project administration, S.Z.; methodology, G.Z.; writing-review and editing, P.G.R. All authors have read and agreed to the published version of the manuscript.

Funding: This research received no external funding.

Conflicts of Interest: The authors declare no competing financial interests.

\section{References}

1. Barber, M. The Crusader States; Yale University Press: New Haven, CT, USA, 2012.

2. Hindley, G. Saladin: Hero of Islam; Pen \& Sword Military: Barnsley, UK, 2007.

3. Hill, P. The Knights Templar at War. 1120-1312; Pen \& Sword Military: Barnsley, UK, 2018.

4. Runciman, S. A History of the Crusades 1: The First Crusade and the Foundation of the Kingdom of Jerusalem/Angla; Penguin Books: Westminster, UK, 2016.

5. Riley-Smith, J. The Crusades: A History; Bloomsbury Academic: London, UK, 2014.

6. Dossa, S.; Maalouf, A. The crusades through arab eyes. MERIP Middle East Rep. 1986, 42, 36-38. [CrossRef]

7. Jones, T.; Ereira, A. Crusades; Penguin Group USA: New York, NY, USA, 1999. 
8. Bradford, E. The Great Betrayal; Open Road Media: New York, NY, USA, 2014.

9. France, J. The Crusades and the Expansion of Catholic Christendom, 1000-1714; Routledge: Oxford, UK, 2006.

10. Madden, T.F. The Crusades Controversy: Setting the Record Straight; North Palm Beach: Wellspring, UK, 2017.

11. Jones, D. Crusaders: The Epic History of the Wars for the Holy Lands; Penguin Books: Westminster, UK, 2019.

12. Stark, R. God's Battalions: The Case for the Crusades; HarperOne: San Francisco, CA, USA, 2009.

13. Carole, H. The Crusades Islam Perspectives; Endinburgh University Press: Edinburgh, UK, 1999.

14. Richard, J. Histoire de Croisades; Fayard: Paris, France, 1996.

15. Pines, M.; Sapir-Hen, L.; Tal, O. Crusader diet in times of war and peace: Arsur (Israel) as a case study. Oxf. J. Archaeol. 2017, 36, 307-328. [CrossRef]

16. Pines, M.; Sapir-Hen, L.; Tal, O. Consumption and disposal practices in the southern levant in late antiquity: Animal bones from 'A $\pi \mathrm{o} \lambda \lambda \omega v i \alpha / \Sigma \omega \zeta \mathrm{ov} \sigma \alpha$ 's hinterland as a case study. Zeitschrift Deutschen Palästina Vereins 2017, 133, $186-204$.

17. Raphael, K.; Tepper, Y. The archaeological evidence from the mamluk siege of arsuf. Mamluk Stud. Rev. 2005, 9, 85-100.

18. Roll, I. Medieval apollonia-arsuf: A Fortified coastal town in the levant of the early muslim and crusader periods. In Autour de la première Croisade. Actes du Colloque de la Society for the Study of the Crusades and the Latin East (Clermont-Ferrand, 22-25 juin 1995); Publications de la Sorbonne: Paris, France, 1996; pp. 597-606.

19. Roll, I.; Ayalon, E. The market street at Apollonia-Arsuf. Bull. Am. Sch. Orient. Res. 1987, 267, 61-76. [CrossRef]

20. Roll, I.; Yohana, H.; Tepper, Y.; Harpak, T. Apollonia-Arsuf during the crusader period in light of new discoveries. Qadmoniot 2000, 33, 18-31. (In Hebrew)

21. Sapir-Hen, L.; Pines, M.; Tal, O. Animal economy and social diversity in Byzantine Apollonia/Sozousa. Levant 2014, 46, 371-381. [CrossRef]

22. Dallongeville, S.; Garnier, N.; Rolando, C.; Tokarski, C. Proteins in art, archaeology, and paleontology: From detection to identification. Chem. Rev. 2016, 116, 2-79. [CrossRef] [PubMed]

23. Guasch-Jané, M.R.; Ibern-Gómez, M.; Andres-Lacueva, C.; Jáuregui, O.; Lamuela-Raventos, R.M. Liquid chromatography with mass spectrometry in tandem mode applied for the identification of wine markers in residues from ancient egyptian vessels. Anal. Chem. 2004, 76, 1672-1677. [CrossRef] [PubMed]

24. Solazzo, C.; Fitzhugh, W.W.; Rolando, C.; Tokarski, C. Identification of protein remains in archaeological potsherds by pro-teomics. Anal. Chem. 2008, 80, 4590-4597. [CrossRef] [PubMed]

25. Dallongeville, S.; Garnier, N.; Casasola, D.B.; Bonifay, M.; Rolando, C.; Tokarski, C. Dealing with the identification of protein species in ancient amphorae. Anal. Bioanal. Chem. 2010, 399, 3053-3063. [CrossRef] [PubMed]

26. Hammann, S.; Cramp, L.J.E. Towards the detection of dietary cereal processing through absorbed lipid biomarkers in archaeological pottery. J. Archeol. Sci. 2018, 93, 74-81. [CrossRef]

27. Hendy, J.; Colonese, A.C.; Franz, I.; Fernandes, R.; Fischer, R.; Orton, D.; Lucquin, A.; Spindler, L.; Anvari, J.; Stroud, E.; et al. Ancient proteins from ceramic vessels at Çatalhöyük West reveal the hidden cuisine of early farmers. Nature Commun. 2018, 9 , 4064-4073. [CrossRef] [PubMed]

28. Tanasi, D.; Cucina, A.; Cunsolo, V.; Saletti, R.; Di Francesco, A.; Greco, E.; Foti, S. Paleoproteomic profiling of organic residues on prehistoric pottery from Malta. Amino Acids 2021, 53, 295-312. [CrossRef] [PubMed]

29. William, S. Itinerarium Peregrinorum et Gesta Regis Ricardi; Eyre \& Spottiswoode: London, UK, 1864.

30. Bulfinch, T. The Age of Chivalry; Reprinted by Dover Publications, 2012; Crosby, Nichols: Boston, MA, USA, 1859.

31. Diderot, D.; D'Alembert, J.B. L'Encyclopédie, 1st ed.; Le Breton: Paris, France, 1751; Volume 4, pp. 502-505.

32. Arouet, F.M. Essai sur les Mours et! Esprit des Nations; Cramer: Paris, France, 1756.

33. Atkins, R.C. Dr. Atkins New Diet Revolution: Revised and Improved; HarperCollins: New York, NY, USA, 2001.

34. Charlier, P.; Poupon, J.; Jeannel, G.-F.; Favier, D.; Popescu, S.-M.; Weil, R.J.; Moulherat, C.; Huynh-Charlier, I.; Dorion-Peyronnet, C.; Lazar, A.-M.; et al. The embalmed heart of Richard the Lionheart (1199 A.D.): A biological and anthropological analysis. Sci. Rep. 2013, 3, 1296. [CrossRef]

35. Ariosto, L. Orlando Furioso; Francesco Libri: Ferrara, Italy, 1516.

36. Tasso, T. Gerusalemme Liberata; Cavalcalupo: Venezia, Italy, 1581. 